\title{
A T-SHAPED RECTANGULAR MICROSTRIP SLOT ANTENNA FOR MID-BAND AND 5G APPLICATIONS
}

\author{
Ajay Thatere ${ }^{1}$, Sachin Khade ${ }^{2}$, Vipul S. Lande ${ }^{3}$, Aditya Chinchole ${ }^{4}$ \\ ${ }^{1,2}$ Yeshwantrao Chavan College of Engineering,Nagpur, India \\ ${ }^{3}$ Shri Ramdeobaba College of Engineering and Management, Nagpur, India \\ Email: $\left\{{ }^{1}\right.$ ajay.thatere@yahoo.co.in, ${ }^{2}$ sac_mob@rediffmail.com, ${ }^{3}$ landevs@ rknec.edu, ${ }^{4}$ adichin1998@gmail.com $\}$
}

\begin{abstract}
A T-shaped rectangular Microstrip slot antenna for mid-band applications like5G bands n48, n77, n78 and other satellite communication applications are portrayed. The proposed antenna has dimension of $35 \times 30 \times 1.6 \mathrm{~mm}^{3}$ and the structure consists Coplanar Waveguide (CPW) with miniaturized size of antenna. The proposed design is embedded on FR4 lossy substrate with dielectric constant of 4.3 and thickness of $1.6 \mathrm{~mm}$. A rectangular slot is etched with dimension of $23 \times 13$ $\mathrm{mm}^{2}$ in which T-shape patch is inserted. The current distribution, gain, directivity, impedance and other simulated results are also presented. The gain and directivity at the resonance frequency of $3.637 \mathrm{GHz}$ is $3.66 \mathrm{~dB}$ and $3.9 \mathrm{dBi}$ respectively. Maximum current is around $125 \mathrm{~A} / \mathrm{m}$ and antenna has a bandwidth of around $1.7 \mathrm{GHz}$
\end{abstract}

Keywords - T-shaped, slot antenna, satellite, 5G.

\section{Introduction}

Microstrip antenna is frequently used antenna for microwave frequencies. Let it be our Wi-Fi broadband or any other communication system like satellite, Microstrip antennas are highly preferred.

Mostly we use the slot antenna to obtain the wide bandwidth by T-shaped Microstrip antenna as this structure of antenna can achieve better impedance match over a wide frequency range through the simple feed structure and also can be easily implemented [1].

Using T-shaped antenna, we are trying to achieve the $5 \mathrm{G}$ bands like n48, n77, n78, n79. Compared to other shapes like inverted F, U-shape, L-shape, $\mathrm{K}$ - shape the T-shape slot antenna has many advantages. Most importantly, it can achieve circular polarization smoothly and attains a wide frequency band range at a very low cost [2].

In this paper we have designed a rectangular slot antenna which is embedded onFR4 lossy having dielectric constant of 4.3 and thickness of $1.6 \mathrm{~mm} \mathrm{[3].}$

The dimension of the substrate is $35 \times 30 \mathrm{~mm}^{2}$ and thickness of $1.6 \mathrm{~mm}$ with CPW feeding. Parameters such as $\mathrm{S}_{11}$, VSWR, impedance, gain, directivity and surface current are studied.

\section{Antenna Structure}

\section{A. Design of proposed antenna}

The structure proposed is T-shaped patch in between a rectangular slot and the side edge patch as shown in the Fig.1.The antenna overall has dimension of $35 \times 30 \mathrm{~mm}^{2}$ and thickness of substrate FR4is $1.6 \mathrm{~mm}$.

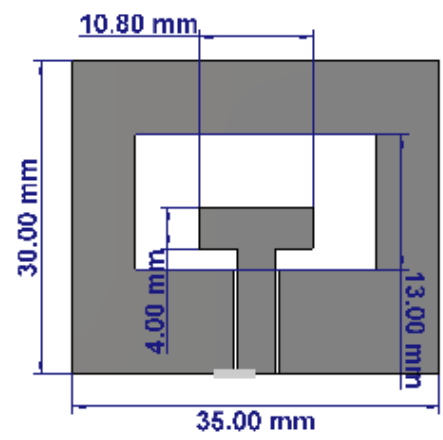

Fig.1 Proposed Antenna structure.
The rectangular slot is $23 \times 13 \mathrm{~mm}^{2}$ and CPW feeding is implemented where both the patch and ground are on the same plane. The T-shaped stub is raised with addition of a small rectangular brick of dimension $10.8 \times 4 \mathrm{~mm}^{2}$.

\section{Simulation Results}

Antenna referred is designed on simulation software name Computer Simulation Technology (CST) Microwave Studios. Simulation results consisting of various antenna parameters such as $S_{11}$, VSWR, Gain, Directivity, etc.

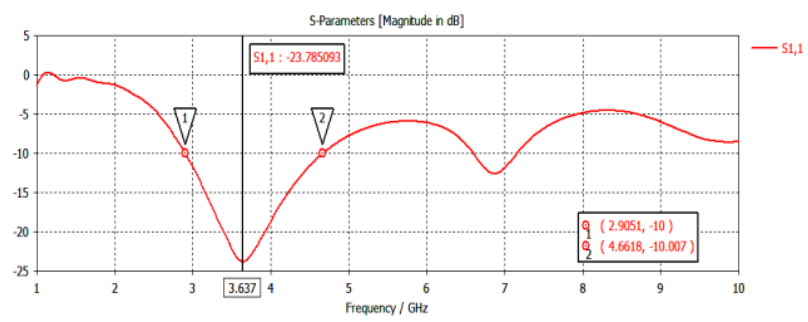

Fig.2 S-parameter results.

The above Fig.2, shows the s-parameter graph in which we can observe frequency band pattern. The observed frequency band range from $2.9-4.66 \mathrm{GHz}$ with resonance at $3.637 \mathrm{GHz}$. The bandwidth is around $1.7 \mathrm{GHz}$. This wide frequency band is used in various applications like $5 \mathrm{G}$ communication, mobile communication and WLAN.

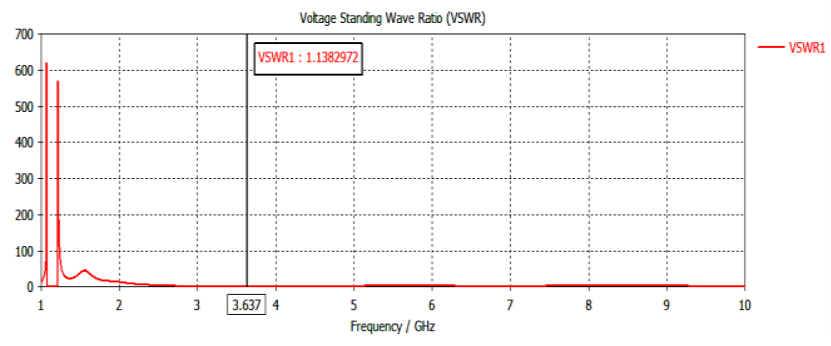

Fig.3 VSWR results at various resonance frequency.

The above Fig. 3 depicts the Voltage Standing Wave Ratio (VSWR) at the resonant frequencies. The observed value is around 1.13.VSWR measures how efficiently the input power is transferred to the load. 


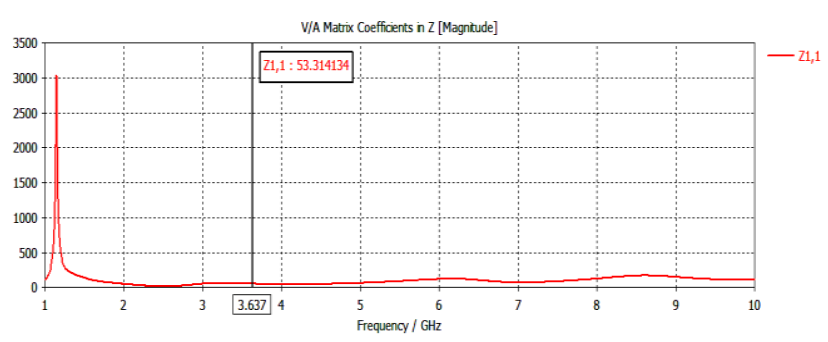

Fig.4 Impedance at $3.637 \mathrm{GHz}$.

Fig.4 depicts the impedance at $3.637 \mathrm{GHz}$ resonant frequency. Ideally, the impedance must be matched at 50 ohms and in this antenna, we have tried to reach to that value.
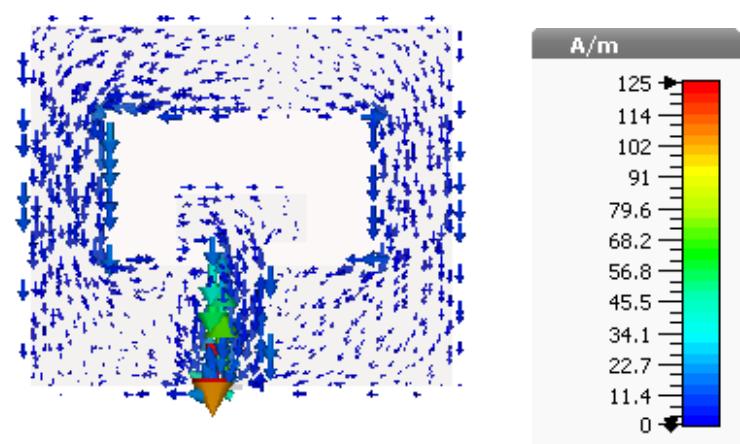

Fig. 5 Surface Current Distribution at $3.637 \mathrm{GHz}$.

Surface current distribution of the antenna has maximum value of $125 \mathrm{~A} / \mathrm{m}$. The directions of the current shows that the antenna can achieve circular polarization. Cirular polarization allows the antenna to catch all types of frequencies which passes near to the position held.
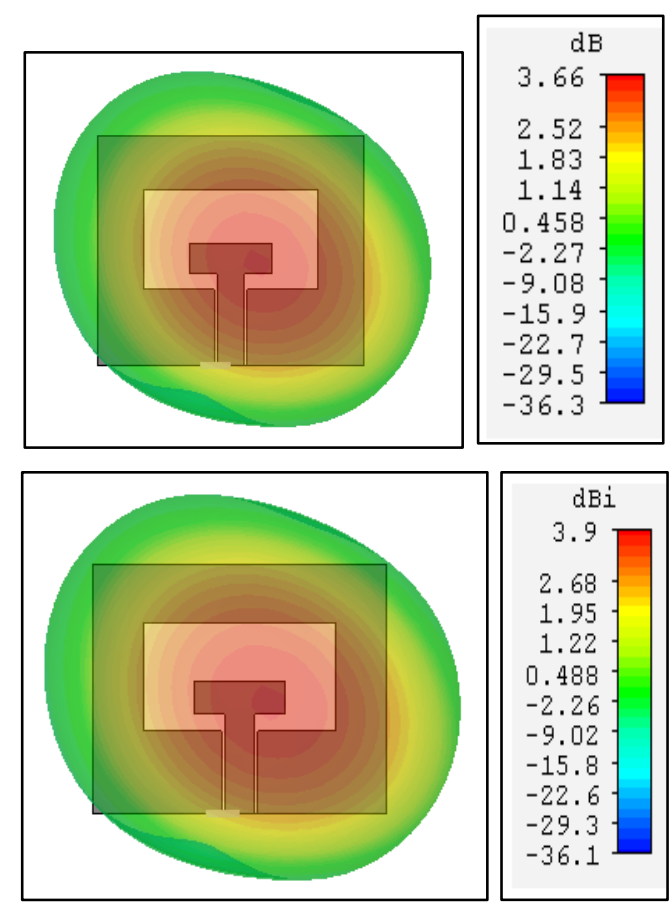

Fig.6 Gain and Directivity results at $3.637 \mathrm{GHz}$.

A 3D view of simulated gain and directivity at $3.637 \mathrm{GHz}$ is portrayed in the Fig.6. At this frequency the gain and directivity of around $3.66 \mathrm{~dB}$ and $3.9 \mathrm{dBi}$ respectively is achieved. Gain and directivity is impressive at this resonance frequency because of the radiation pattern as shown in Fig. 9 below.

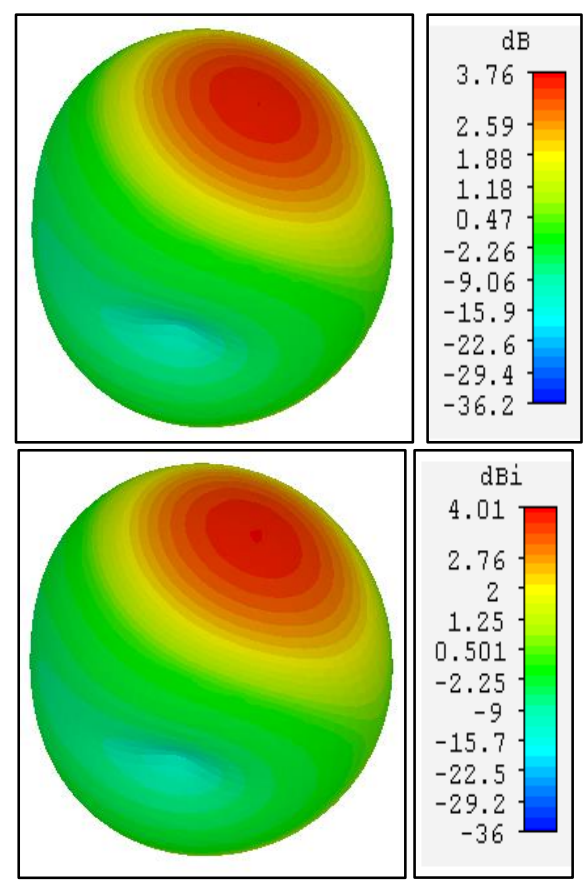

Fig.7 Gain and Directivity at $3.8 \mathrm{GHz}$.

Now we will have a look at gain and directivity measurements at $3.8 \mathrm{GHz}$ frequency. Here we can see in Fig.7 that gain and directivity achieved is approximately around $3.76 \mathrm{~dB}$ and $4.01 \mathrm{dBi}$ respectively. This frequency has application in $5 \mathrm{G} \mathrm{n} 48, \mathrm{n} 77$ and $\mathrm{n} 78$ band with 3.355-3.7 $\mathrm{GHz}, 3.3-4.2 \mathrm{GHz}$ and 3.3-3.8 GHz respectively as uplink and downlink frequency covering around $500 \mathrm{MHz}$ bandwidth.

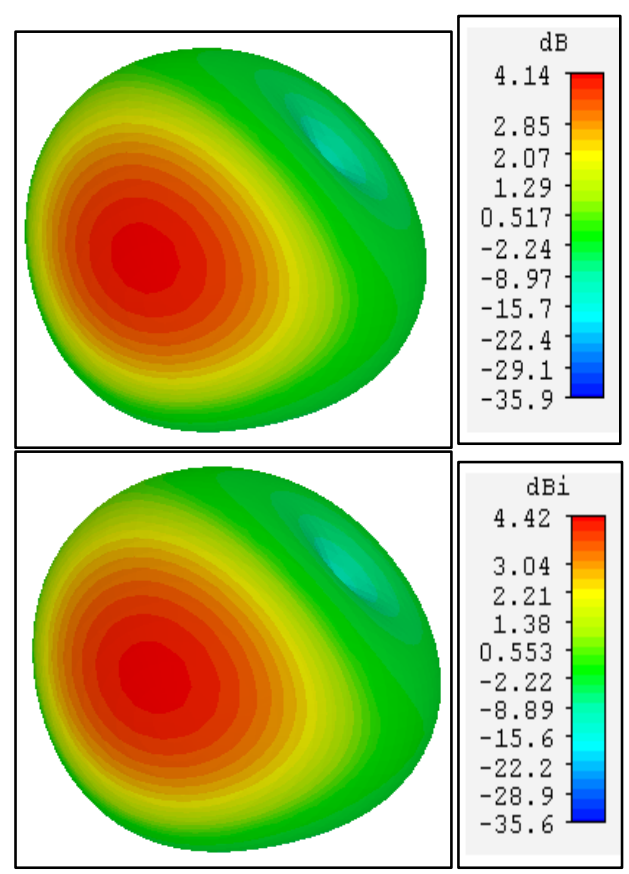

Fig.8 Gain and Directivity at $4.5 \mathrm{GHz}$.

Another frequency of $4.5 \mathrm{GHz}$ has attained gain of $4.14 \mathrm{~dB}$ and directivity of $4.42 \mathrm{dBi}$, depicted in the Fig.8. Gain and Directivity is higher as compared to previous frequencies. This frequency is allotted for $5 \mathrm{G}$ in various Asian countries like China and Japan. The 5G n79 bands have uplink frequency of $4.4 \mathrm{GHz}$ and downlink frequency $5 \mathrm{GHz}$. 

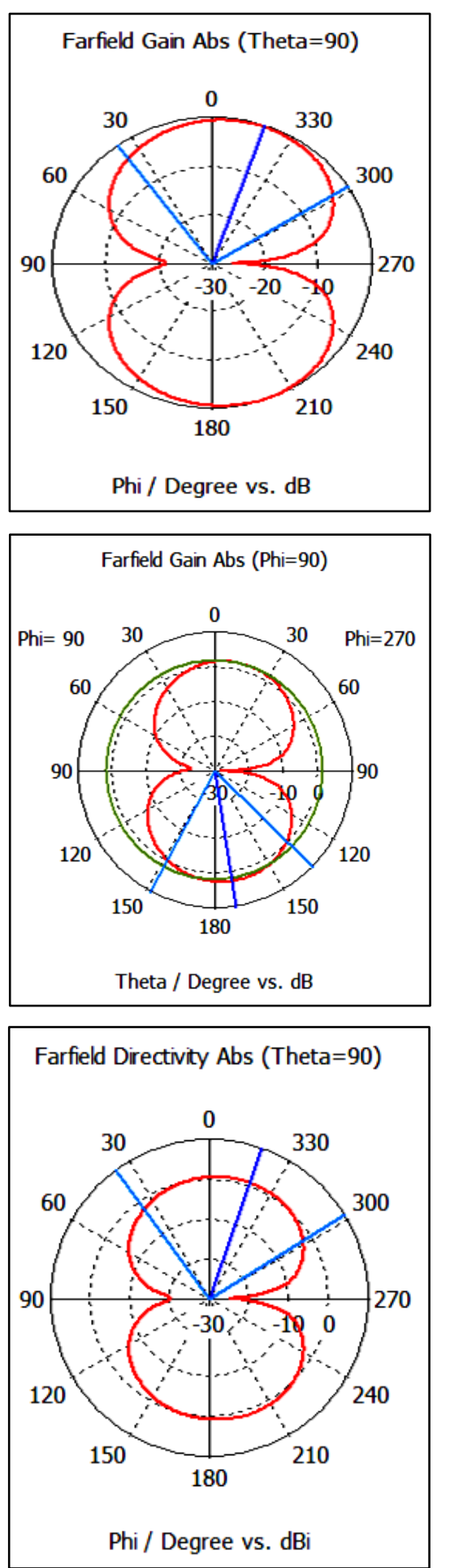

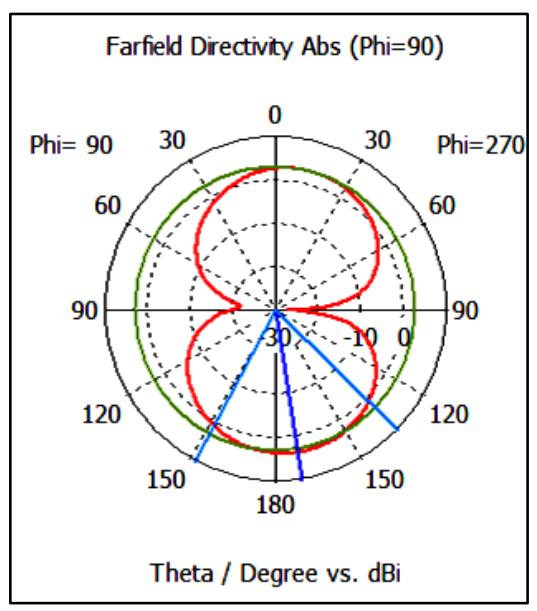

Fig.9 Radiation pattern at constant phi and theta at $3.8 \mathrm{GHz}$ and $4.5 \mathrm{GHz}$

\section{Conclusion}

The proposed T-shaped rectangular slot antenna was analyzed and its parameters and results behavior were studied. Frequency band range of 2.9-4.66 GHz was observed in the reflection coefficient results with resonance at 3.637 GHz.The gain and directivity are $3.66 \mathrm{~dB}$ and 3.9 $\mathrm{dBi}$. The surface current is $125 \mathrm{~A} / \mathrm{m}$. The $5 \mathrm{G}$ bands $\mathrm{n} 48$, $\mathrm{n} 77$ and $\mathrm{n} 78$ are attained. The frequencies attained are useful for satellite communication and other telecommunication purpose.

\section{References}

[1] Y. Lin and K. Hung, "Compact Ultrawideband Rectangular Aperture Antenna and Band-Notched Designs," in IEEE Transactions on Antennas and Propagation, vol. 54, no. 11, pp. 3075-3081, Nov. 2006, doi: 10.1109/TAP.2006.883982.

[2] A. Chinchole and S. Khade, "A Wideband Slot Antenna with Simple Structure," 2020 International Conference on Emerging Trends in Information Technology and Engineering (ic-ETITE), Vellore, India, 2020, pp. 1-5, doi: 10.1109/icETITE47903.2020.338.

[3] V.Magare, S. Khade and A. Chinchole, "Comparative study of circularly polarized patch antenna using multiple substrates," 2020 International Conference on Emerging Trends in Information Technology and Engineering (ic-ETITE), Vellore, India, 2020, pp. 1-5, doi: 10.1109/ic-ETITE47903.2020.444.

[4] R.F. Harrington, Time-Harmonic Electromagnetic Fields. NewYork: McGraw-Hill, 1961. 